\title{
Obese women and in vitro fertilization: results
}

\author{
Joana Gonçalves Koatz ${ }^{1}$, Maria do Carmo Borges de Souza² \\ ${ }^{1}$ Instituto Sapientiae \\ 2 Fertipraxis RJ Centro de Reprodução Humana \\ Accredited Redlara centre
}

\begin{abstract}
Objective: To evaluate the effect of female obesity on the results of In Vitro Fertilization (IVF) in six parameters: dose of gonadotropins required, number of oocytes retrieved and fertilization, pregnancy, miscarriage and live births rates. Method: Literature search in PUBMED articles in English between 2008 and 2013 using the following keywords: female, obesity and In Vitro Fertilization. 15 articles were selected for this work.

Results: From the total only two articles showed that female obesity does not alter the results of IVF. The remaining 13 came to the conclusion that obesity has a negative effect on some of the parameters evaluated. However, there was no consensus about its effect.

Conclusion: Further studies are needed to clarify the real role of obesity in female patients undergoing IVF, but the weight loss prior to treatment should always be encouraged. Keywords: Female, Obesity and In Vitro Fertilization.
\end{abstract}

\section{RESUMO}

Objetivo: Avaliar o efeito da obesidade feminina nos resultados da fertilização in vitro (FIV) em seis parâmetros: dosagem de gonadotrofinas utilizadas, número de oócitos recuperados e fertilização, gravidez, aborto e taxas de nascidos vivos.

Método: Pesquisa bibliográfica em artigos PUBMED em Inglês, entre 2008 e 2013, utilizando as seguintes palavraschave: mulher, obesidade e fertilização in vitro. 15 artigos foram selecionados para este trabalho.

Resultados: Do total apenas dois artigos mostraram que a obesidade feminina não altera os resultados de fertilização in vitro. Os restantes 13 chegaram à conclusão de que a obesidade tem um efeito negativo sobre alguns dos parâmetros avaliados. No entanto, não houve consenso sobre o seu efeito.

Conclusão: Mais estudos são necessários para esclarecer o real papel da obesidade em pacientes do sexo feminino submetidas a fertilização in vitro, mas a perda de peso antes do tratamento deve ser sempre incentivada.

Palavras-chave: feminino, obesidade e fertilização in vitro.

\section{INTRODUCTION}

Obesity, characterized by excess triglycerides in fat cells (Erel et al., 2009) and defined as a body mass index $\geq 30$ $\mathrm{kg} / \mathrm{m}^{2}$ is becoming a growing problem for the entire world population. BMI is calculated by dividing body weight in kilograms by height in meters squared, according to the criteria of the World Health Organization (WHO). Using this classification, the population can be divided into four groups: underweight when the BMI is less than or equal to $18.5 \mathrm{~kg} / \mathrm{m}^{2}$, normal between 19 and $24.9 \mathrm{~kg} / \mathrm{m}^{2}$, overweight between 25 and $29.9 \mathrm{~kg} / \mathrm{m}^{2}$ and obese when greater than or equal to $30 \mathrm{~kg} / \mathrm{m}^{2}$. Obese may be further divided into classes: Class I with BMI 30 to $34.9 \mathrm{~kg} / \mathrm{m}^{2}$, Class II 35 to $39.9 \mathrm{~kg} / \mathrm{m}^{2}$ and class III when greater than or equal to $40 \mathrm{~kg} / \mathrm{m}^{2}$. In the last decade, the global trend shows an increase of about $40 \%$ of overweight and obesity in women of reproductive age (Erel et al., 2009).
Obesity has become a worldwide epidemic, with approximately 1.6 billion adults being overweight and 400 million obese (Prentice, 2006; WHO, 2006). In Brazil, according to the Ministry of Health in 2012, $17 \%$ of the population are obese and $51 \%$ overweight. So it has become a major challenge to public health in many countries. The increased prevalence is the result of a combination of reduced physical exercise, changes in the composition of the diet and increased caloric intake. The deleterious effects of obesity on health in general are well known, including diabetes mellitus, hypertension, gastroesophageal reflux disease and hepatic steatosis. On human reproduction it leads to menstrual disorders, infertility and maternal complications during pregnancy.

The reduced fertility in obese women is likely related to multiple factors that include changes in metabolic and endocrine functions, which in turn can affect follicular development, implantation and development of clinical pregnancy. A delay in spontaneous conception is seen in obese, especially for ovulatory changes, but also in women with regular cycle, which reduces the likelihood of pregnancy $5 \%$ per unit of BMI exceeding $29 \mathrm{~kg} / \mathrm{m} 2$ ( Loveland et al., 2009).

Clinical observations on the effect of body weight on assisted reproduction techniques of high complexity are controversial. The objective of this work is to evaluate the effect of female obesity on the outcome of in vitro fertilization (IVF) in relation to the dose of gonadotropins required for ovarian stimulation, number of oocytes retrieved and fertilization, miscarriage, pregnancy and live birth rates.

\section{MATERIALS AND METHODS}

Literature search were conducted in PUBMED, selecting works in English from 2008 to 2013, using the following keywords: female, obesity and In Vitro Fertilization. We found 17 references of which 15 were used in this study. The two excluded studies addressed patients with Polycystic Ovary Syndrome (PCOS). Among the selected, two are systematic reviews and 13 original papers (11 retrospectives).

\section{RESULTS}

Clinical observations on the effect of female body weight during IVF and Intracytoplasmic Sperm Injection (ICSI) are very controversial. Obesity may adversely affect the results of Assisted Reproductive Therapy (ART) through changes in the duration of ovarian stimulation, the dose of gonadotropins required, the estradiol peak, the number of mature follicles, number of oocytes retrieved and cycle cancellation, fertilization, cleavage, embryo transfer, number of live births . abortion and pregnancy rates. Six parameters were evaluated: required dose of gonadotropins, number of oocytes retrieved after ovarian stimulation and fertilization, pregnancy, miscarriage and live births rates.

\section{DOSE OF GONADOTROPINS}

Regarding the dose of gonadotropins required for ovarian stimulation, most articles (nine out of 11 ) show that obese 
patients require higher doses. Ritterberg et al., 2011 showed an increase in the dose of gonadotropins in 5 studies (WMD $406.77,95 \%$ CI 169.26 to $644.2, p=0.0008)$. In the study of Moragianni et al., 2012, obese patients required higher doses of gonadotropins in relation to patients with BMI in normal range: $2908.47 \pm 1478.91$ versus 2844.88 $\pm 1918.80(p=0.02)$ and dose was also higher in patients with class II and III obesity. In Fox - Zander et al., 2012, the dose in obese was $213.4 \pm 6.1$, while in patients with normal BMI was $201.5 \pm 2.7(p<0.05)$. Singh et al., 2012 also achieved significant results with a $p$ value of 0.04 , showing that obese patients requiring larger doses as well as the work of Pinborg et al., 2011, whose $p$ value was 0.01 . In Orvieto et al., 2009, about $30 \pm 15$ ampoules were used in patients which BMI was less than 30 and $38 \pm 15$ ampoules in obese patients $(p<0.001)$. Zhang et al., 2010 showed that the dose in patients with BMI in the normal range was $2587 \pm 933$ and $3272 \pm 1798$ in obese $(p<$ 0.05). In Bellver et al., 2010, this result was also found with $p$ value of 0.001 . In Erel et al., 2009 review, several articles were evaluated. Some have shown that higher dose it is necessary, while in others not. In the article of Sathya et a.I, 2010, the dose was similar between BMI classes. And Vilarino et al. (2011) found no statistical difference in dose.

\section{NUMBER OF OOCYTES RETRIEVED}

This topic was assessed in nine articles, and in 3 of them the number recovered after ovarian puncture was lower in obese women. In Zander - Fox et al., 2012 the number was $10.5 \pm 0.2$ in patients with normal BMIs, and $9.2 \pm 0.4$ in obese $(p<0.05)$. In Pinborg et al., 2011, was $9.9 \pm 5.3$ to $8.3 \pm 5.8(p<0.01)$, as illustrated in Figure 1 , and in Zhang et al., $201014,49 \pm 7.96$ to $12.48 \pm 5.89(p<0.001)$. In the meta-analysis of Rittenberg et al., 2011, there was no statistical difference between the BMI, as in Singh et al., 2012 in which the $p$ value was 0.679 and the Vilarino et al. 2011 1. In Bellver et al., 2010, there was no difference: the patients with BMI between 20 and $24.9 \mathrm{~kg} / \mathrm{m}^{2}$ had on average $12.6 \pm 8.0$ oocytes and obese $13.0 \pm 8.8$. In Erel et al., 2009 not reached a consensus. And Sneed et al., 2008, the number of oocytes was related mainly to the interaction BMI and age of the woman and not only with BMI.

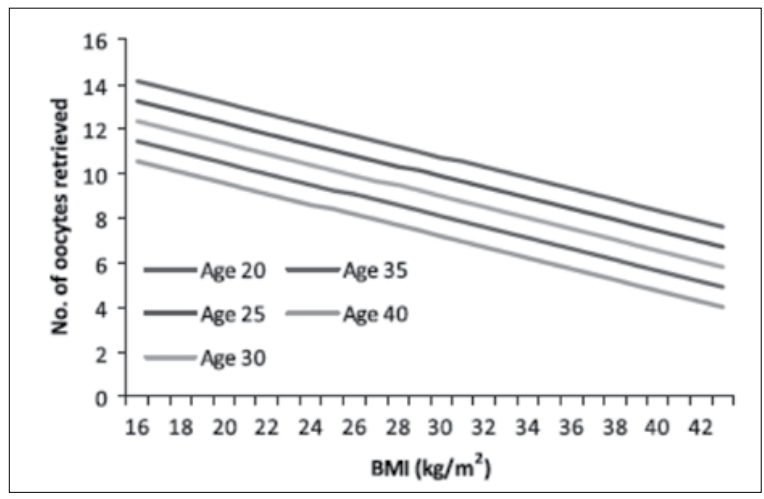

Figure 1. Expected number of oocytes retrieved related to BMI and age women. A stepwise multiple linear regression, including only the first IVF / ICSI, showed a significant negative association between the number of oocytes retrieved and BMI $(P<0.001, \mathrm{~B}=-0243, \mathrm{SE}=0.059)$ and age of women $(P=0.014, \mathrm{~B}=-0179, \mathrm{SE}=0.073)$. Adapted from Pinborg et al., 2011.

\section{FERTILIZATION RATE}

Nine articles examined the fertilization rate (FR), and only two showed that obesity has a negative effect on the process. These items are: Zhang et al., 2010 (Table 1) and Orvieto et al., 2009. In the first article, obese patients had a fertilization rate of $54.1 \pm 21.3 \%$ versus $61.1 \pm 23 \%$ in the normal range, $p<0.001$. In the second, the obese FR were $46 \pm 24 \%$ and in normal BMI and $55 \pm 22 \%$ with $p<$ 0.02. In Erel et al., 2009 a literature review was performed and most studies have not demonstrated a significant difference between patients with different BMI.

Zander - Fox et al., 2012, Singh et al., 2012, Vilarino et al., 2011, Bellver et al., 2010 and Sathya et al., 2010 have not shown significant change of obesity on the fertilization rate. Sneed et al., 2008, showed that the interaction between BMI and age of women was significant in fertilization rate, however, BMI alone had no apparent effect. This had a greater impact on patients under 36 years, because in older women age became the most important factor.

\section{PREGNANCY RATE}

Thirteen articles assessed this outcome, five showed that this rate is negatively affected by obesity. One is the study of Rittenberg et al., 2011, which evaluated 15 articles and showed reduction in pregnancy rate (PR) in obese patients (RR $0.87,95 \%$ CI 0.80 to $0.95, \mathrm{p}=$ 0.002 ). In the study by Bellver et al., 2010 the cumulative pregnancy rate was $92.3 \%$ in normal patients, $89.2 \%$ in overweight patients, $93.7 \%$ in the group with BMI $<20 \mathrm{~kg} / \mathrm{m}^{2}$ and $87.1 \%$ women with BMI $\geq 30 \mathrm{~kg} / \mathrm{m}^{2}$. And the PR dropped from $44.8 \%$ in patients with BMI within the normal range for $37.9 \%$ in obese patients ( $p$ $=0.03$ ). In the study of Orvieto et al., 2009 the PR was found to be $27.97 \%$ in non- obese and $15.4 \%$ in obese $(p<0.01)$. In Moragianni et al., 2012, after adjusting for different variables, it was found that PR was significantly lower in obese. In Singh et al., 2012 the rate fell from 31.2 to $21.6 \%$ in obese patients with $p$ value of 0.045 (Figure 2). Erel et al. conducted a review in 2009 and obtained as result that some articles have shown that the rate is affected by obesity, while other items that do not, ie, without conclusive result. In Chavarro et al., 2012 Pinborg et al., 2011, Vilarino et al., 2011, Sathya et al., 2010 and Zhang et al., 2010 although the results are suggestive of the negative impact of obesity, there was no significant difference. Zander - Fox et al., 2012 showed that pregnancy rates were similar between obese and non-obese $(p<0.05)$.

In Sneed et al., 2008, there was no significant impact of BMI isolated at that rate, but the interaction between BMI and age of the woman. So,younger patients ( $<36$ years) had their results changed by BMI while older not.

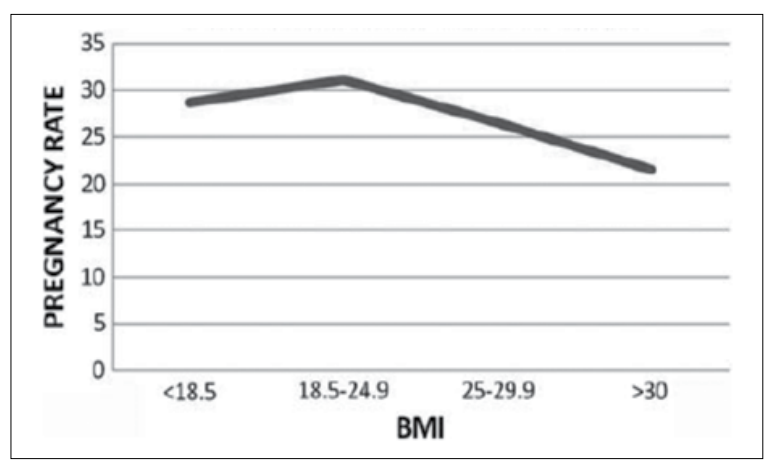

Figure 2. Pregnancy rate in the different BMI groups. Adapted from Singh et al., 2012.

\section{MISCARRIAGE RATE}

Seven of the articles addressed this topic, and only two showed that this rate is increased in obese patients. One was the study of Veleva et al. (2008), which showed that the BMI graph curve that represents how BMI affects the miscarriage rate is U-shaped, meaning that patients of low weight also has their increased risk, 
Table 1. Ovarian stimulation and IVF results in patients

\begin{tabular}{lcccc}
\hline Groups & Normal weight $(\boldsymbol{n}=\mathbf{2 2 2 2})$ & Overweight $(\boldsymbol{n}=\mathbf{3 7 9})$ & Obesity $(\boldsymbol{n}=\mathbf{2 7})$ & $\boldsymbol{p}$ value \\
\hline Cycle cancellation & $205(9.2 \%)$ & $22(5.8 \%)$ & $1(3.7 \%)$ & $>0.05$ \\
\hline Days of stimulation & $10.42 \pm 2.03$ & $10.60 \pm 2.16$ & $11.89 \pm 4.57^{*}$ & $<0.001$ \\
\hline Gn dose $(\mathrm{IU})$ & $2,587 \pm 933$ & $2,688_{ \pm} 966^{* *}$ & $3272 \pm 1798^{*}$ & $<0.001^{*},<0.05^{* *}$ \\
\hline Peak $\mathrm{E}_{2}(\mathrm{pmol} / \mathrm{L})$ & $13,757 \pm 10,212$ & $11,307 \pm 8,999$ & $10290 \pm 9048$ & $>0.05$ \\
\hline Oocytes retrieved & $14.49 \pm 7.96$ & $12.98 \pm 6.91^{*}$ & $12.48 \pm 5.89$ & $<0.001$ \\
\hline Fertilised eggs & $8.87 \pm 5.96$ & $7.72 \pm 4.85^{*}$ & $6.78 \pm 4.16$ & $<0.001$ \\
\hline Fertilisation rate $(\%)$ & $61.1 \pm 23.0$ & $60.8 \pm 23.3^{*}$ & $54.1 \pm 21.3^{*}$ & $<0.001$ \\
\hline Cleavaged embryos & $8.67 \pm 5.90$ & $7.55_{ \pm} 4.86^{*}$ & $6.96 \pm 4.25$ & $<0.001$ \\
\hline High-grade embryos & $5.59 \pm 4.81$ & $4.65 \pm 3.96^{*}$ & $4.56_{ \pm} 2.94$ & $<0.001$ \\
\hline Cryopreserved embryos & $5.49 \pm 5.55$ & $4.44 \pm 4.55^{*}$ & $3.81 \pm 4.01$ & $<0.001$ \\
\hline Numbers of embryos tranferred & $2.15 \pm 0.90$ & $2.30 \pm 0.84$ & $2.19 \pm 0.68$ & $>0.05$ \\
\hline Continuous
\end{tabular}

Continuous data were analysed using one-way ANOVA test, and post-hoc comparisons were performed using the LSD test. Chi-square test was used to assess the categorical variables.

${ }^{*} p<0.001$, compared with the normal weight group.

$* * p<0.05$, compared with the normal weight group.

Adapted from Zhang et al., 2010.

independent of patient age ( Figure 3 ). Moreover, the revision of Rittenberg et al., 2011 revealed increased miscarriage rate in 14 studies (RR 1.36, $95 \%$ CI 1.13 to $1.64, p=0.001$ ). In Bellver et al., 2010, despite the rate being increased, this increase was not significant, as in Vilarino et al., 2011, Zhang et al., 2010 and Sathya et al .,2010.

Sneed et al., 2008 showed that miscarriage rate is not directly affected by BMI, but by the interaction between BMI and age, with age the main determining factor.

\section{LIVE BIRTH RATE}

Of the 15 selected articles, 9 evaluated whether obesity alter the live birth rate (LBR). The result was that 5 showed that obesity decreased and 4 who did not alter it. Among the studies showing this effect, Petersen et al., 2012 showed a $25 \%$ reduction in LBR (95\% CI 0.63-0.90) in the obese women. From the trend analysis, a statistically significant decrease of $2 \%(95 \%$ CI $0,79-0,99)$ was observed with every 1-unit increase in BMI $(p=0,003)$. In case of ICSI, the relationship between BMI and rate of live births was not well established, although there is a trend toward a reduction of this rat. Another article also demonstrates that this reduction: Chavarro et al., 2012 showed a LBR of $23 \%$ in obese patients, $30 \%$ in patients with BMI $22.5-24.9$ and $42 \% 20-22,4 \mathrm{~kg} / \mathrm{m}^{2}(p=0.03)$. Moragianni et al., 2012 showed that compared with patients with normal BMI, the chance of live births in obese decreases by $37 \%$ in class I, $61 \%$ in class II and $68 \%$ in class III. Rittenberg et al., 2011, presented a systematic review in which 5 studies also showed a reduction in this rate (RR $0.80,95 \% \mathrm{CI} 0.70$ to $0.90, p=0.0002$ ).

In Pinborg et al., 2011 there was no statistical difference between the different classes of BMI $(p=0.06)$. As in the Vilarino et al., 2011 in which the $p$ value was greater than 0.05. Bellver et al, 2010 divided the patients into 4 groups according to their BMI: <20, 20 to $24.9,25$ to 29.9 , and greater than $30 \mathrm{~kg} / \mathrm{m}^{2}$. The LBR in patients within the normal range was $31.3 \%$ and $23.7 \%$ in obese patients $(p=0.01)$. The odds ratio for each point of BMI increased above the normal unit is 0.981 (95\% CI 0.967 to 0.995$)$ for the LBR $(p=0.009)$.

Zhang et al., 2010 showed that there was no difference in this rate between patients with normal weight, overweight and obese ( $26.2 \%$ vs $23.7 \%$ vs $26 \%$, respectively) with $p$ value greater than 0.05 . In Sneed et al., 2008 was evidenced significant interaction between BMI, age of the woman and IVF results. The effect of BMI was strongly related to patient's age and can't be regarded as an isolated factor.
Table 2. The Results Table

\begin{tabular}{lcccccc}
\hline ARTICLES & DG & OR & FR & PR & MR & LBR \\
\hline PETERSEN 2012 & NM & NM & NM & NM & NM & $\downarrow$ \\
\hline CHAVARRO 2012 & NM & NM & NM & $\downarrow$ & NM & $\downarrow$ \\
\hline SINGH 2012 & $\uparrow$ & $=$ & $=$ & $\downarrow$ & NM & NM \\
\hline ZANDER-FOX 2012 & $\uparrow$ & $\downarrow$ & $=$ & $=$ & NM & NM \\
\hline MORAGIANNI 2012 & $\uparrow$ & NM & NM & $\downarrow$ & NM & $\downarrow$ \\
\hline RITTENBERG 2011 & $\uparrow$ & $=$ & NM & $\downarrow$ & $\uparrow$ & $\downarrow$ \\
\hline PINBORG 2011 & $\uparrow$ & $\downarrow$ & NM & $\downarrow$ & NM & $=$ \\
\hline VILARINO 2011 & $=$ & $=$ & $=$ & $=$ & $=$ & $=$ \\
\hline BELLVER 2010 & $\uparrow$ & $=$ & $=$ & $\downarrow$ & $=$ & $\downarrow$ \\
\hline SATHYA 2010 & $=$ & NM & $=$ & $=$ & $=$ & NM \\
\hline ZHANG 2010 & $\uparrow$ & $\downarrow$ & $\downarrow$ & $=$ & $=$ & $=$ \\
\hline ORVIETO 2009 & $\uparrow$ & NM & $\downarrow$ & $\downarrow$ & NM & NM \\
\hline EREL 2009 & $\uparrow$ & $\downarrow$ & $\downarrow$ & $\downarrow$ & NM & NM \\
\hline SNEED 2008 & NM & $=$ & $=$ & $=$ & $=$ & $=$ \\
\hline VELEVA 2008 & NM & NM & NM & NM & $\uparrow$ & NM \\
\hline DG DOS Of GOndOtro & OR & ODCyteveds Rer & & &
\end{tabular}

DG - Dose of Gonadotropin/ OR - Oocyteveds Retri / FR -

Fertilization Rate / PR - Pregnancy Rate / MR - Miscarriage Rate / LBR - Live Births Rate / NM - Not Measured

\section{DISCUSSION}

Obesity has become a worldwide epidemic and thus the number of obese women seeking treatment for assisted reproduction increased. Therefore, the impact of the increased BMI on IVF results has become of paramount importance to patients and physicians. As seen in this work, although the majority of the articles show that obesity has a negative effect on some of the parameters analyzed, there is no consensus in the literature about their real consequences. The articles on the subject have found mixed results, which difficult a generalization of results. Some have a very small population sample and others were conducted in populations whose characteristics are quite distinct from the others, as is the case in the study by Zhang et al. (2010), in which the study population was Chinese, with different anthropometric characteristics of Westerners.

Also, another factor that hampers the generalization is the difference in types of ART protocol used. The studies reviewed are not standardized in relation to medication use , time of use, laboratory parameters, data collection on history, number of cycles performed, among other factors. Most studies are retrospective, thus there is no way to control 


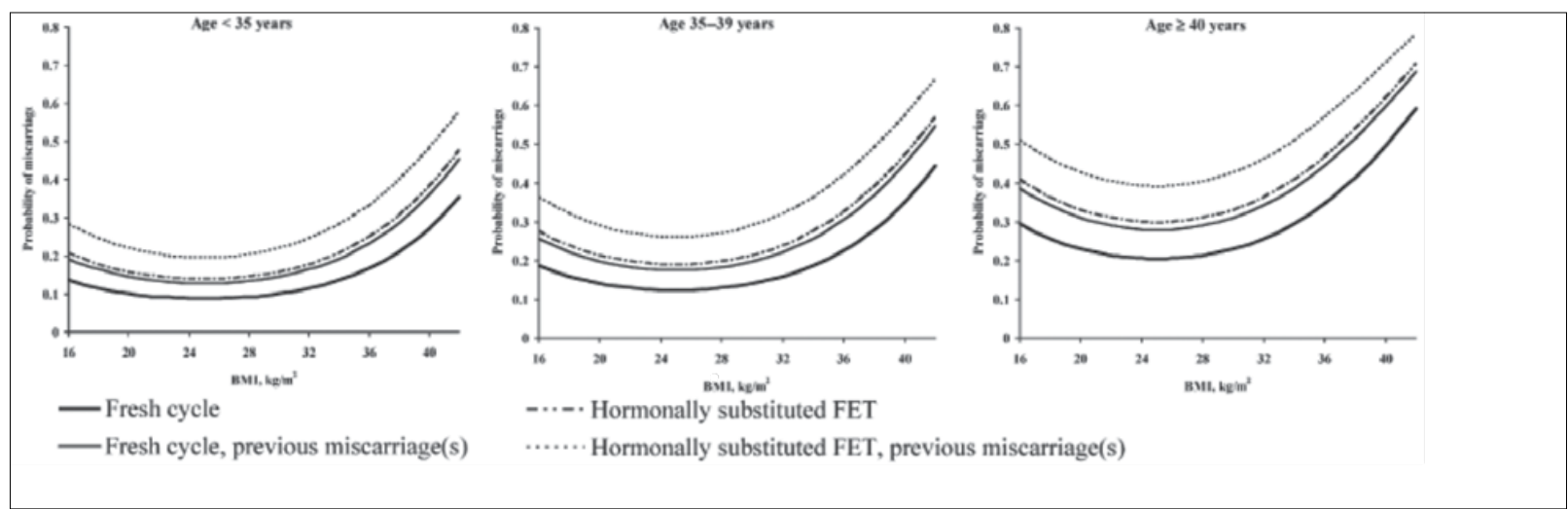

Figure 3. Modeled probability of miscarriage in different age groups. Adapted from Veleva et al., 2008.

for confounding factors such as age, whether the patient is a poor responder or if she has PCOS and/or endometriosis. Some do not differentiate overweight obesity, low BMI with normal and many are not free of biases.

The age of the patient is known to be one of the most important factors for IVF outcome, however, many articles did not differentiate by age group, which decreases the reliability of their results.

One of the biggest studies was that of Rittenberg et al. (2011), that despite adding a large number of works, presents heterogeneity among them, which makes their results have to be interpreted with caution. Moreover, it was not possible to adjust factors like age, cause and duration of infertility, stimulation protocol used and the number and quality of embryos transferred.

The work Pinborg et al. (2009), with a longitudinal follow-up for 5 years, allowed an adjustment of confounding factors such as social class and duration of infertility. On the other hand, did not clarify the number of cycles for each patient. What is also observed is that some cases are often lost or missing basic data as the reference weight or BMI in patients included. Likewise, lack of follow-up on the treatment period or interval between cycles, and modifications of these data. Regarding the MR, the studies do not make clear whether the patients have had previous miscarriage, which itself increases the chance of recurrence.

Also, some authors wonder if the effect of obesity would not actually on endometrial quality and not on the oocyte and/ or embryo quality.

A consensus on female obesity is that her complications during pregnancy are more frequent, such as the development of gestational diabetes and toxemia, fetal macrosomia, cephalopelvic disproportion and greater indication caesareans .

\section{CONCLUSION}

Current data indicate increased BMI as a disadvantage to obtain pregnancy in an IVF cycle. Although the data is not fully established, it is suggested advice for weight loss prior to treatment.

\section{Correspondence}

Joana G Koatz

Email: jokoatz@yahoo.com.br

\section{REFERENCES}

Bellver J, Ayllon Y, Ferrando M, Melo M, Goyri E, Pellicer A, Remohí J, Meseguer M. Female obesity impairs in vitro fertilization outcome without affecting embryo quality. Fertil Steril., Vol. 93, No.2, January 15, 2010.
Chavarro J.E, Ehrlich S, Colaci D.S, Wright D.L, Toth T.L, Petrozza J.C, Hauser R. Body mass index and short-term weight change in relation to treatment outcomes in women undergoing assisted reproduction. Fertil Steril., Vol.98, No.1, July 2012 0015-0282.

Erel C.T, Senturk L.M. The impact of body mass index on assisted reproduction. Curr Opin Obstet Gynecol., 2009, 21:228-235.

Moragianni V.A, Jones S.M.L, Ryley D.A. The effect of body mass index on the outcomes of first assisted reproductive techonology cycles. Fertil Steril., Vol.98, No.1, July 2012 0015-0282.

Orvieto R, Meltcer S, Nahum R, Rabinson J, Anteby E.Y, Ashkenazi J. The influence of body mass index on in vitro fertlization outcome. Int J Gynaecol Obstet.104 (2009) 53-55.

Petersen G.L, Schmidt L, Pinborg A, Kamoer-Jorgensen M. The influence of female and male body mass index on live births after assisted reproductive technology treatment: a nationwide register-based cohort study. Fertil Steril., 2013.

Pinborg A, Gaarsley C, Hougaard C.O, Andersen A.N, Andersen P.K, Boivin J, Schmidt L. Influence of female bodyweight on IVF outcome: a longitudinal multicentre cohort study of 487 infertile couples. Reprod Biomed Online., 2011, 23, 490-499.

Rittenberg V, Seshadr S. S, Sunkara K, Sobaleva S, Otng-Ntim E, El-Toukhy T. Effect of body mass index on IVF treatment outcome: an updated systematic review and meta-analysis. Reprod Biomed Online., 2011, 23, 421-439.

Sathya A, Balasubramanyam S, Gupta S, Verma T. Effect of body mass index on in vitro fertilization outcomes in women. J Hum Reprod Sci., 2010 Sep-Dec; 3 (3): 135-138.

Singh N, Gupta P, Mittal S, Malhotra N. Correlation of body mass index with outcome of in vitro fertilization in a developing country. Arch Gynecol Obstet., 2012, 285:259-263.

Sneed M.L, Uhler M.L, Grotjan H.E, Rapisarda J.J, Lederer K.J, Beltsos A.N. Body mass index: impact on IVF sucess appears age-related. Hum Reprod., Vol.23, No.8 pp. 1835-1839, 2008.

Veleva Z, Tiitinem A, Vilska S, Hydén-Granskog C, Tomás C, Martikainen $\mathrm{H}$, Tapanainen J.S. High and low BMI increase the risk of miscarriage after FIV/ICSI and FET. Hum Reprod.,Vol.23, No.4 pp. 878-884, 2008.

Vilarino F.L, Christofolini D.M, Rodrigues D, Souza A.M.B, Christofolini J, Bianco B, Barbosa C.P. Body mass index and fertility: is there a correlation with human reproduction outcomes? Gynecol Endocrinol., April 2011; 27(4): 232-236.

Zander-Fox D.L, Henshaw R, Hamilton H, Lane M. Does obesity really matter? The impact of BMI on embryo quality and pregnancy outcomes after IVF in women age $\leq 38$ years. Aust $N$ Z J Obstet Gynaecol., 2012; 52: 270-276.

Zhang D, Zhu Y, Gao H, Zhou B, Zhang R, Wang T, Ding G, Qu $F$, Huang $H$, Lu X. Overweight and obesity negatively affect the outcomes of ovarian stimulation and in vitro fertilization: a cohort study of 2628 Chinese women. Gynecol Endocrinol., May 2010; 26(5): 325-332. 